Article

\title{
Analysis of an Attached Sunspace with a Thermal Inertia Floor
}

\author{
María José Suárez López * (iD, Antonio José Gutiérrez Trashorras, Jorge Luis Parrondo Gayo ${ }^{(D)}$ \\ and Eduardo Blanco Marigorta
}

Campus de Viesques, Universidad de Oviedo, EDZE (Energía), 33203 Gijón (Asturias), Spain; antonio.gutierrez@uniovi.es (A.J.G.T.); parrondo@uniovi.es (J.L.P.G.); eblanco@uniovi.es (E.B.M.)

* Correspondence: suarezlmaria@uniovi.es; Tel.: +34-985-182-114

Received: 2 April 2018; Accepted: 24 April 2018; Published: 3 May 2018

\begin{abstract}
An attached sunspace is a partially or fully glazed enclosure, usually located on the first floor, facing south (in the Northern Hemisphere) and adjacent to a conditioned room. Because of the length and orientation of the glazed area, the temperature in the sunspace is usually higher than outside the building. As a Trombe-Mitchel wall, the sunspace has a considerable mass that accumulates thermal energy, but in this case the thermal mass is located in the floor. This capacity to accumulate thermal energy confers the attached sunspace features beyond passive insulation. The sunspace studied in this paper is part of an experimental building located in the North of Spain that was built in the frame of the so-called ARFRISOL project. It consists of a south-facing glazed exterior wall with both clear glass and semi-transparent photovoltaic panels, an intermediate space with a thick layer of sand over a concrete floor, and a partially glazed interior wall. In this paper, a three-dimensional computational model has been implemented to analyse the thermal behaviour inside the sunspace. This analysis takes into account, among other factors, the effects of sun position, incident solar irradiation and temperature both inside and outside.
\end{abstract}

Keywords: sunspace; CFD (computational fluid dynamics); energy-efficient buildings; solar passive design

\section{Introduction}

In the analysis of energy consumption, users are traditionally classified in three sectors: industry, buildings and transport. In particular, the buildings sector-consisting of households, commercial and office buildings-has the highest percentage of energy consumption in developed countries (around $40 \%$ ) [1]; therefore, it is also one of the main emission sources. Within this sector, the largest use of energy (above 50\%) corresponds to the thermal conditioning of buildings (heating in winter and cooling in summer).

Energy efficiency and bioclimatic architecture were two of the pillars of the Strategic Singular Project, named ARFRISOL (Arquitectura Bioclimática y Frío Solar = Bioclimatic Architecture and Solar Cooling), organized and promoted by the Spanish Education and Science Authority. This project studied the energy behaviour of five demonstration-containers (new or renovated buildings) located at five sites in Spain each with a different climatic condition. The aim was to explore the combination of passive conditioning systems (ventilated façade, sunspace, glass corridor, etc.) and renewable energy sources (solar energy, biomass, geothermal energy, etc.) to reduce conventional energy consumption and emissions above $80 \%$ [2]. One of the passive solutions tested was an attached sunspace located in a demonstration container in the North of Spain. The main purpose of that sunspace was to check its capability to reduce the amount of energy used in the heating of the building by taking advantage of the solar radiation. 
In bioclimatic architecture, an attached sunspace (or greenhouse) is a solution employed in detached houses that can be considered as an-in façade-overheating system with thermal inertia. It is usually composed of a glazed exterior wall facing south (in the Northern Hemisphere), an intermediate enclosed room with thermal inertia, and a back wall that can be partially glazed and separates the sunspace from one or more interior rooms (Figure 1). Regarding to thermal behaviour in the Bioclimatic Architecture concept, sunspaces are designed to accumulate thermal energy in the floor zone (although sometimes also in the wall) by means a considerable thermal mass, which may be constituted by sand, gravel, concrete or water, for example.

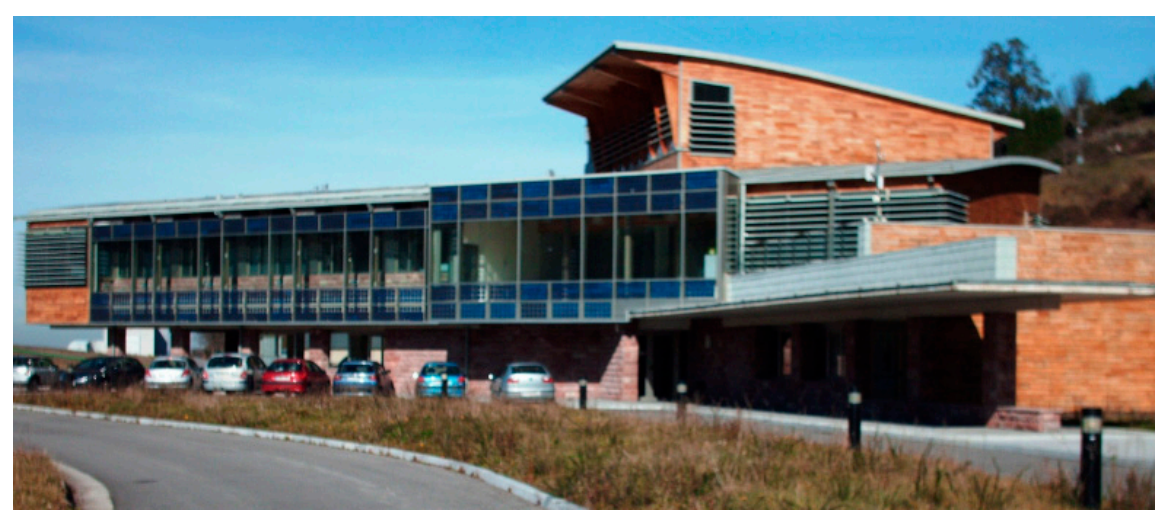

Figure 1. Demonstration container with attached sunspace (south side) located at San Pedro de Anes, Asturias (northern Spain).

The attached sunspace now analysed is located in a special experimental building in Asturias, in northern Spain (Figure 1). The exterior of the sunspace (Figure 2) is a glazed wall facing south, composed of simple transparent glass in the central stripe and semi-transparent photovoltaic panels on both the upper and lower parts. Figure 3 shows the interior space with the intermediate glass and wall partition that separate the sunspace from the hall and meeting room of the building. It also shows two air grilles on the back wall, which are passages that can be connected to the Heating, Ventilation and Air Conditioning HVAC system of the building, so that the sunspace could be used to support the air-conditioning equipment in winter.



Figure 2. External glazed surface of the attached sunspace in the demonstration-container. 


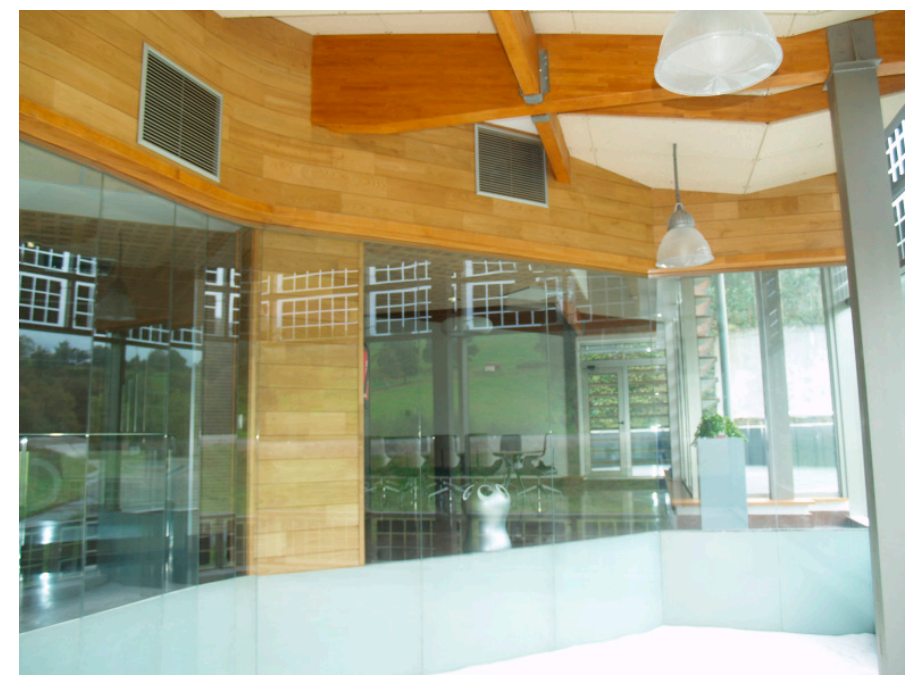

Figure 3. Interior wall (partially glazed) in the attached sunspace.

This article presents a numerical study on the thermal behaviour of the attached sunspace throughout the year. The conventional analytical and parametric simulation models available in the literature cannot be used because they are not able to calculate shadow effects in the convoluted sunspace geometry nor the effective solar radiation when using different types of exterior glass. Instead, this research was based on a computational fluid dynamics (CFD) tool with a special simulation methodology devised to cope with the complex thermal and fluid dynamic phenomena involved. In particular, a special user-defined function (UDF) has been developed to determine the solar radiation in the interior of the sunspace. This UDF takes into account the variation of sun position, the solar radiation intensity and the exterior air temperature as a function of time. The analysis considers the solar irradiation on the glazed surface and the heat transmission to the adjacent rooms, both directly through the internal glazed areas and indirectly through the opaque surfaces (vertical and horizontal ones).

\section{Literature Review}

Leaving aside the various designs used in traditional architecture, passive solar techniques can be said to have been developed in the last 150 years. In 1881, the first patent was given to Edward L. Morse for the glazed wall built in his house (U.S. Patent 246,626). This system is the precursor of the Trombe wall, one of the techniques most used over the years [3].

However, specific scientific literature on passive heating systems (including Trombe walls, glazed galleries and attached greenhouses or sunspaces) began to appear much later, in the 1980s. Two of these early studies were the transwall analysis by Fuchs and McClelland [4] and the "Passive Solar Design Handbook" by Jones [5]. Models to determine the heat transfer and storage were also developed after checking the performance of several bioclimatic systems. Some of them were implemented by using simple numerical simulations [6,7], including attempts of model validation by contrast with experimental techniques [8,9]. Many authors have tried to compare the performance of different bioclimatic solutions $[10,11]$. There is not a clear winner but the elements including glazed spaces are usually in the head positions $[4,12,13]$.

With respect to the experimental studies on attached sunspaces, Schoenau et al. [14] monitored four sunspaces operating in a cold climate and compared the results. Bakos and Tsagas [15] analysed the thermal behaviour in a real sunspace located in the North of Grecia and Mihalakakou [16] studied the use of the greenhouse in different European climatic zones.

Regarding the analytical models, the first ones were relatively simple net models $[4,17]$, not specifically intended for sunspaces. Later, more complex analytical models were developed to simulate 
and evaluate the thermal performance of direct solar gain in glazed spaces. Some of them were contrasted against experimental data obtained in prototypes (both laboratory- and full-scale) $[14,18,19]$.

Besides, there have been several parametric studies in which real sunspaces located in different cities were analysed by means of different dynamic simulation softwares including DEROB-LTH, TRNSYS, ESP-r and DOE-2 [20-23]. A recent tendency is to study the thermal performance of real attached sunspaces by using whole-building dynamic simulation tools (EnergyPlus, IDA-ICE) [24-26]. Also, some of them evaluate not only the energy efficiency of these passive solar solutions but the potential energy savings as a function of different configurations $[25,27]$.

Numerical models based on computational fluid dynamics techniques (CFD) began to be applied to renewable energy in buildings in the 1990s, and these techniques have been widely employed for both active and passive solar solutions. However, papers presenting applications of these numerical models to the case of glazed enclosures are rather uncommon, mostly because of the difficulty of integrating the solar radiation characteristics. Guohui [28], Xiande and Yuanzhe [29] used CFD models to simulate the thermal behaviour of a Trombe wall, considering the natural convection in steady state. Chen and Liu [30] conducted a numerical analysis of the heat transmission through a solar wall with a porous absorbent (similar to a Trombe-Michel wall). Also, our research team analysed the stationary thermal behaviour of a glazed corridor, first by developing a 2D model [31] and later a 3D one [32].

Given the scarcity and limitations of those analyses, a simulation methodology based on CFD techniques appears as an attractive alternative to study the thermal behaviour of attached sunspaces, because of their high capacity to achieve a close description of the details of the internal air flows and heat transfer phenomena of interest. This is the purpose of the study now reported.

\section{Solar Radiation and Sun Position Analysis}

The solar radiation data used in the simulations have been established following the ASHRAE method [33] adjusted with the data from the Asturias Solar Map [34] developed by the University of Oviedo in the frame of the ARFRISOL project. They have also been compared with the experimental measurements from the weather station nearby the demonstration container.

Firstly, the solar radiation on a surface perpendicular to the rays $\left(E_{0}, \mathrm{~W} / \mathrm{m}^{2}\right)$ is calculated based on the day of the year $(n)$ and a solar constant $\left(E_{s c}\right)$ :

$$
E_{0}=E_{s c} \cdot\left[1+0.033 \cdot \cos \left(360 \cdot \frac{(n-3)}{365}\right)\right]
$$

The solar constant is defined as the incident intensity of solar radiation on a surface perpendicular to the rays in the Earth's atmosphere halfway between the sun and the Earth. According to the World Meteorological Organization (WMO), its value is $1367 \mathrm{~W} / \mathrm{m}^{2}$ [35].

Secondly, the sun's position is calculated as a function of different parameters. The equation for time (ET, in minutes) is defined depending on the day of the year $(n)$ :

$$
E T=2.2918 \cdot(0.075+0.1868 \cdot \cos (\Gamma)-3.2077 \cdot \sin (\Gamma)-1.4615 \cdot \cos (2 \Gamma)-4.089 \cdot \sin (2 \Gamma)),
$$

where,

$$
\Gamma=\frac{360 \cdot(n-1)}{365} .
$$

The apparent solar hour (AST, in hours) is calculated as a function of standard solar time (LST, in hours), equation of time (ET), longitude of standard meridian (LSM, degrees East of Greenwich), and longitude of the place (LON, degrees East of Greenwich):

$$
A S T=L S T+\frac{E T}{60}+\frac{L O N-L S M}{15} .
$$


The longitude of standard meridian is determined according to the time zone (TZ, in hours):

$$
L S M=15 \cdot T Z
$$

Then, the solar declination, defined as the angle between the Earth-sun line and the equatorial plane, is calculated ( $\delta$, degrees). This parameter changes throughout the year and is responsible for the seasons.

$$
\delta=23.45 \cdot \sin \left(360 \cdot \frac{(n+284)}{365}\right)
$$

Once the above parameters have been calculated, the sun's position is obtained depending on the solar altitude $(\beta)$ and azimuth $(\phi)$. The solar altitude varies between $0^{\circ}$ and $90^{\circ}$ during the day, while these values are negative during the night. The azimuth has been internationally accepted as positive in the afternoon and negative in the morning. These two parameters depend on the latitude (L) and the hour angle $(H)$. In this case, the demonstration container is located in San Pedro de Anes (Siero, Asturias, north of Spain), whose latitude is $5.699619^{\circ} \mathrm{N}$. The hour angle $(H$, in degrees) is defined as the sun's angular displacement in eastern or western local meridian due to Earth's rotation.

$$
H=15 \cdot(A S T-12)
$$

This parameter is negative in the morning and at night, zero in the solar noon (this moment corresponds to the maximum solar altitude) and positive in the afternoon.

Solar altitude and azimuth are calculated by the following equations:

$$
\begin{gathered}
\sin (\beta)=\cos (L) \cdot \cos (\delta) \cdot \cos (H)+\sin (L) \cdot \sin (\delta), \\
\sin (\phi)=\frac{\sin (H) \cdot \cos (\delta)}{\cos (\beta)} .
\end{gathered}
$$

Also, the sun's position in spherical coordinates is determined from the two parameters mentioned above, for use in the numerical simulations.

Finally, the direct $\left(E_{b}, \mathrm{~W} / \mathrm{m}^{2}\right)$ and diffuse $\left(E_{d}, \mathrm{~W} / \mathrm{m}^{2}\right)$ solar radiation in a clear day are calculated. Both depend on the incident solar irradiation $\left(E_{0}, \mathrm{~W} / \mathrm{m}^{2}\right)$, the relative air mass $(m)$, and the direct and diffuse radiation optical depths ( $\tau_{b}$ and $\tau_{d}$, respectively).

$$
\begin{gathered}
E_{b}=E_{0} \cdot \exp \left(-\tau_{b} \cdot m^{a b}\right), \\
E_{d}=E_{0} \cdot \exp \left(-\tau_{d} \cdot m^{a d}\right), \\
m=\frac{1}{\sin (\beta)+0.50572 \cdot(6.09995+\beta)^{-1.6364}} .
\end{gathered}
$$

The values of $\mathrm{ab}$ and ad are estimated according to the direct and diffuse radiation optical depths:

$$
\begin{aligned}
& a b=1.219-0.043 \cdot \tau_{b}-0.151 \cdot \tau_{d}-0.204 \cdot \tau_{b} \cdot \tau_{d}, \\
& a d=0.202+0.852 \cdot \tau_{b}-0.007 \cdot \tau_{d}-0.357 \cdot \tau_{b} \cdot \tau_{d} .
\end{aligned}
$$

These two dimensionless parameters $\tau_{b}$ and $\tau_{d}$, depend on the location and the day of the year ([32] shows the values in Atlanta as an example). In our case, the values were adjusted to match the data in the Asturias Solar Map [34] and the results have been compared with experimental measurements of solar radiation in San Pedro de Anes (Siero, Asturias). These calculations have been made for an average day in each season. The selected days are the 15th of March, June, September and December. In Figure 4 the solar radiation determined for the 15th of March is shown: direct and diffuse solar radiation (calculated using the ASHRAE method) and global solar radiation on horizontal surface 
(found by combining both of them), together with the instantaneous global radiation on horizontal surface (calculated with the experimental data measured in the nearby weather station during 2009 and 2010).

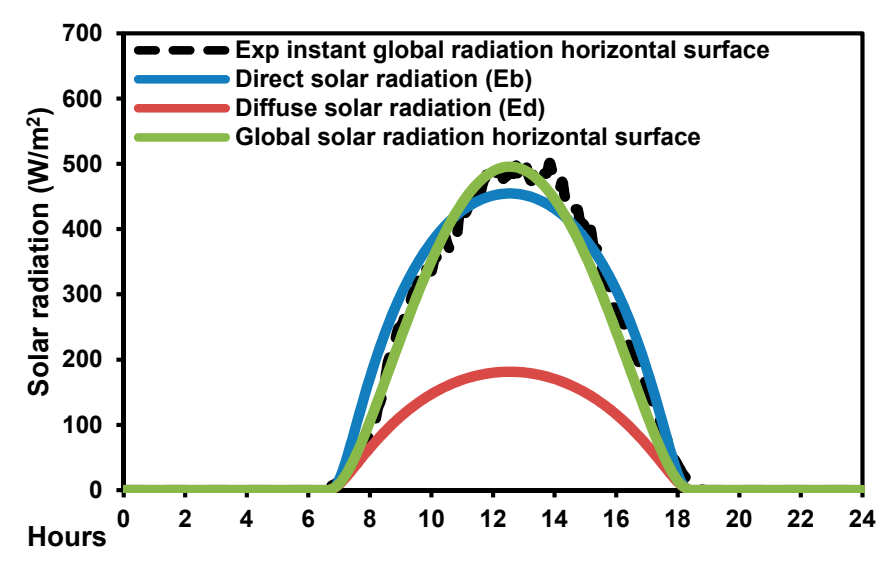

Figure 4. Solar radiation data for the 15th of March.

\section{Methodology}

The numerical simulation of the attached sunspace has been performed using the CFD code ANSYS 12.1, which solves the unsteady-state Reynolds averaged Navier-Stokes equations through the finite volume method. Figure 5 presents the discretized 3D geometry of the calculation domain. This includes the sunspace and the neighbouring rooms, which are separated by an $S$ shaped interior partition partially glazed (as seen in Figure 3).

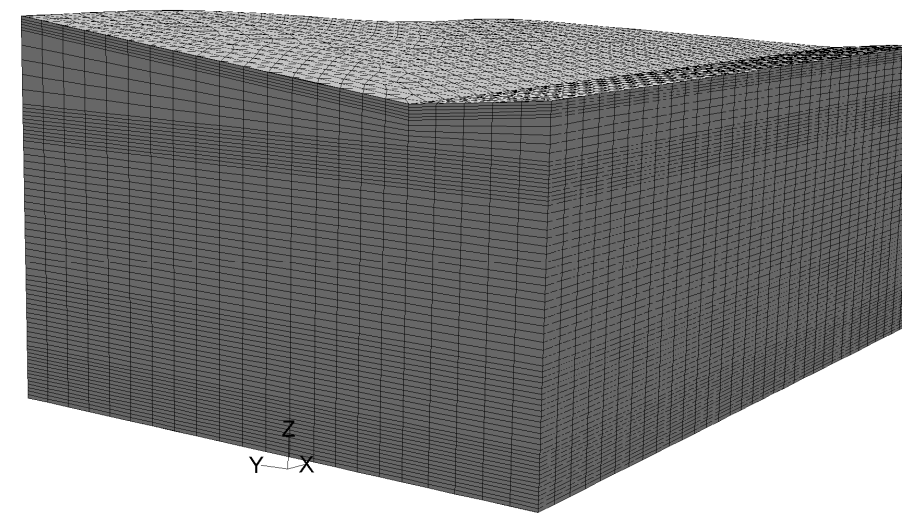

Figure 5. Geometry and mesh of the calculation domain (attached sunspace at the right side of the image).

The domain was discretized with an unstructured mesh formed by triangular prism cells (Figure 5). The mesh was refined at the regions where with potentially higher field gradients, mostly near the floor and ceiling. Opaque and semi-transparent materials were also meshed to include the computation of heat conduction through the internal solid partitions.

To assure good calculation accuracy, second order discretization was selected for the governing equations at each cell. Besides, the convergence criterion to conclude the iterative computational process at each time step was established in a value of $10^{-5}$ for the normalised residuals of each governing equation.

In order to estimate the uncertainty of the numerical predictions, the Richardson's extrapolation method [36] was used based on the calculations for several meshes with different cell size. This included 
meshes with total number of cells ranging from about 125,000 to 1,000,000. The difference between the average air temperature in the attached sunspace achieved with the coarsest mesh and the value obtained from Richardson's extrapolation is lower than $0.25^{\circ} \mathrm{C}$ on average, whereas with the finest mesh it is lower than $0.06^{\circ} \mathrm{C}$. All subsequent computations were performed with the one million cell mesh.

In passive solar solutions in general, and especially in attached sunspaces, a large part of the heat transfer takes place by radiation. After a thorough examination of the available radiation models, the Discrete Ordinates method [37] was chosen, mainly because of its ability to simulate the radiation through semi-transparent materials such as glass. In this model, the heat radiation is solved for a certain number of solid angles. These angles are defined by divisions and pixels with a direct influence on the accuracy of the solution. Five divisions and 16 pixels (higher than default) were chosen as a compromise between numerical resources and computation time. This method also allows visible radiation to be differentiated from infrared radiation. The former is defined by a band with wavelengths ranging from 0.4 to $2.9 \mu \mathrm{m}$, and the latter has a band from 2.9 to $1000 \mu \mathrm{m}$. As indicated below, the radiation absorption coefficients of the semi-transparent materials are different for each band.

Turbulence effects in the fluid flow were incorporated by means of the K-epsilon-RNG model [38], including buoyancy effects. Chen [39] found out that this turbulence model produced the best results for cases with features similar to the current test case.

The fluid used in the simulation is air considered as an ideal gas, i.e., the local density is updated at every time step by using the ideal gas equation. Regarding the solid materials, the floor and the roof are made of a concrete slab, which can be considered equivalent to $20 \mathrm{~cm}$ of concrete and $20 \mathrm{~cm}$ of insulation. In the floor, above the concrete there is a layer of $20 \mathrm{~cm}$ of sand. The opaque walls are made of a layer of insulation $(10 \mathrm{~cm})$ and concrete $(20 \mathrm{~cm})$. The opaque part of the interior partition has an overlay of wood $(1 \mathrm{~cm})$. It was assumed that the net heat transfer through the floor, roof and opaque walls is negligible compared to the glazing. All these materials were considered to be opaque to radiation, with an emissivity value of 0.9 and a diffuse reflection value of $1 \%$. Table 1 shows the properties of these materials.

Table 1. Properties of the materials.

\begin{tabular}{cccc}
\hline Material & Density $\left(\mathbf{k g} / \mathbf{m}^{\mathbf{3}}\right)$ & Specific Heat $(\mathbf{J} / \mathbf{k g} \cdot \mathbf{K})$ & Thermal Conductivity $(\mathbf{W} / \mathbf{m} \cdot \mathbf{K})$ \\
\hline Concrete & 2000 & 1050 & 2 \\
Sand & 1400 & 795 & 0.5 \\
Insulation & 40 & 1000 & 0.041 \\
Wood & 700 & 2310 & 0.173 \\
Glass & 2220 & 830 & 1.03 \\
\hline
\end{tabular}

The exterior glazing of the attached sunspace was divided into three zones (Figure 3): a central region consisting of single-sheets of laminated glass with $1 \mathrm{~cm}$ in thickness and the upper and lower zones, which are translucent photovoltaic modules composed of photovoltaic cells imbedded in the glass. Their thickness and thermal characteristics are similar to the central glazing. The interior glazing is like the central part of the exterior glazing as well. The glazing is semi-transparent to radiation and different absorption coefficients have been used for the laminated glass and the translucent photovoltaic modules. For the first one, the absorption coefficient was set to $30 \mathrm{~m}^{-1}$ in the visible band and $450 \mathrm{~m}^{-1}$ in the infrared band, while in the second case it was set to $163.30 \mathrm{~m}^{-1}$ in the visible band and $566.94 \mathrm{~m}^{-1}$ in the infrared band. The refractive index was 1.52 in both cases [40].

The thermal boundary conditions assumed on the glazed surfaces at the contour of the domain take into account the heat transmitted by convection and radiation. The convection heat transfer coefficients were set to $23 \mathrm{~W} / \mathrm{m}^{2} \cdot \mathrm{K}$ for the outer side of the exterior glazing and $8 \mathrm{~W} / \mathrm{m}^{2} \cdot \mathrm{K}$ for the glazing in the partition wall, in accordance to the European standard EN-673 (UNE-EN-673). The radiation on the interior glazing was considered as diffuse radiation (originated in the building 
interior), and is determined by imposing the temperature of the source to be similar to the ambient temperature. For the radiation on the exterior glazing, experimental data have been used together with variables calculated by the ASHRAE method explained above. Finally, an emissivity value of 0.837 was used for both the interior and exterior glazing on their respective surfaces facing outwards (UNE-EN-673).

The interior air temperature was considered to be $21^{\circ} \mathrm{C}$ in winter conditions and $26^{\circ} \mathrm{C}$ in summer, according to the current regulations for buildings in Spain [41]. The exterior air temperature was measured in situ.

\section{Unsteady Calculation and UDF}

To simulate the time evolution of the system during specific days along the year, unsteady computations were performed with a time step of $5 \mathrm{~min}$, which gives 288 time steps per day. The air temperature, the sun position and solar radiation, both direct and diffuse, at each time instant were imposed by using a User-Defined Function (UDF). This is a specially designed routine written in C language and compiled for its integration in the CFD code used.

The UDF operates as follows. First, in the initialization section, the UDF loads an external file with a list of instantaneous data including exterior temperature, sun position vector, direct radiation and diffuse fraction. The list covers one complete day, usually with values at every $5 \mathrm{~min}$. If the computational instant of time is not coincident with any time instant available in the list, then the UDF performs an interpolation to estimate the required instantaneous data. Besides, another subroutine has been defined to set the exterior temperature for the convective heat transfer at the exterior walls. All these conditions are to be applied on a set of surfaces defined in the file header. During the computational process, the UDF determines the radiation and temperature values at each iteration and applies them to specific variables of the corresponding surfaces.

This UDF has been designed to run either in series, i.e., with one process node, or parallel, so that several nodes are used to increase the computation velocity. In the last case, the UDF distributes the data to all the calculation nodes and there they are assigned to the corresponding cells.

\section{Results}

\subsection{Simulations}

As explained above, unsteady simulations have been performed to analyse the thermal behaviour of an attached sunspace subject to changing environmental conditions during one day. The calculation process starts with a steady simulation performed at midnight conditions. Then the converged solution is used to initialize the variables at each node of the domain for the subsequent unsteady calculations. And finally, unsteady simulations are performed covering several identical days, until the predicted time signals exhibit a regular periodic pattern with constant amplitude.

The analysis of the sunspace performance has been conducted for four days, one in each season of the year: the 15th of March, June, September and December. The solar radiation employed in the simulation has been calculated by using the ASHRAE method as explained in the third section of this paper. The exterior air temperature has been taken as the average of the experimental data for those specific days in the period 2009 to 2012.

As an example of the resulting predictions, Figure 6 presents the temperature contours on the interior surfaces on the 15th of March at 11:00 a.m., with a solar radiation of $597.4 \mathrm{~W} / \mathrm{m}^{2}$ and an exterior air temperature of $9.8^{\circ} \mathrm{C}$. The interior average air temperature achieved is about $15^{\circ} \mathrm{C}$. In this figure the internal glazing is a little warmer than the interior air, but only a little, because most of the solar radiation it receives is being transferred to the adjacent rooms. The opaque walls situated below the glazing might be expected to be warmer than the glazing itself, due to their insulation properties. However, they also have more inertia and at the instant of Figure 6 they are even a little 
cooler. Regarding the floor, the area directly illuminated by the sun can be clearly distinguished, because there the sand is much warmer.

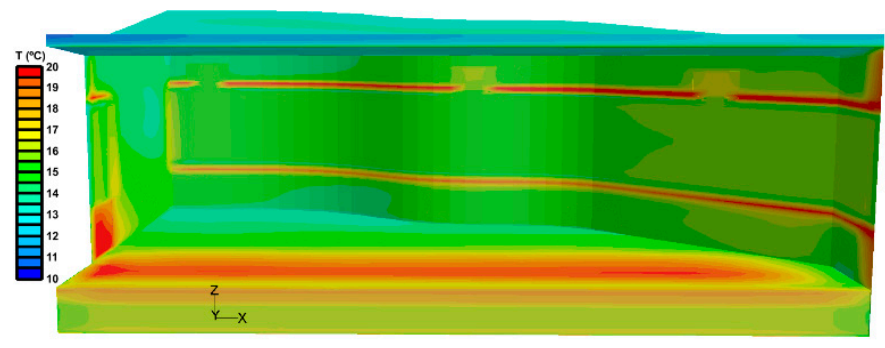

Figure 6. Temperature contours on the interior surfaces: vertical partition, sand floor and ceiling. Date: 15th March at 11:00 a.m.; solar irradiation $597.43 \mathrm{~W} / \mathrm{m}^{2}$; exterior temperature $9.8^{\circ} \mathrm{C}$.

\subsection{Validation}

The numerical model was contrasted by using experimental data collected in the sunspace and thermographs of different interior zones. The temperature of the air inside the attached sunspace was measured by means of three PT-100 platinum thermoresistances, situated at different heights in the central position of the sunspace. The thermographs were taken with a FLIR camera model P40. Also, the solar irradiation and the external air temperature were determined from a nearby weather station with data recorded at five minute intervals from 2009 to 2012, although only the values for the specific days selected have been used in this study.

Figure 7 shows an example of the temperature evolution for the 15th of March of 2010. During that day there were few clouds and the temperature values were similar to the average during that month. The values of the exterior air temperature and solar radiation (on horizontal surface) are represented in this figure together with the interior air temperature, both experimental and numerical. The average difference between these temperatures is less than $1.5^{\circ} \mathrm{C}$. As it can also be seen in the figure, during this day near of the beginning of spring, the interior air temperature is always higher than the exterior one. This difference is highest at midday: while the interior air is almost at $30^{\circ} \mathrm{C}$, the temperature outside remains below $15^{\circ} \mathrm{C}$.

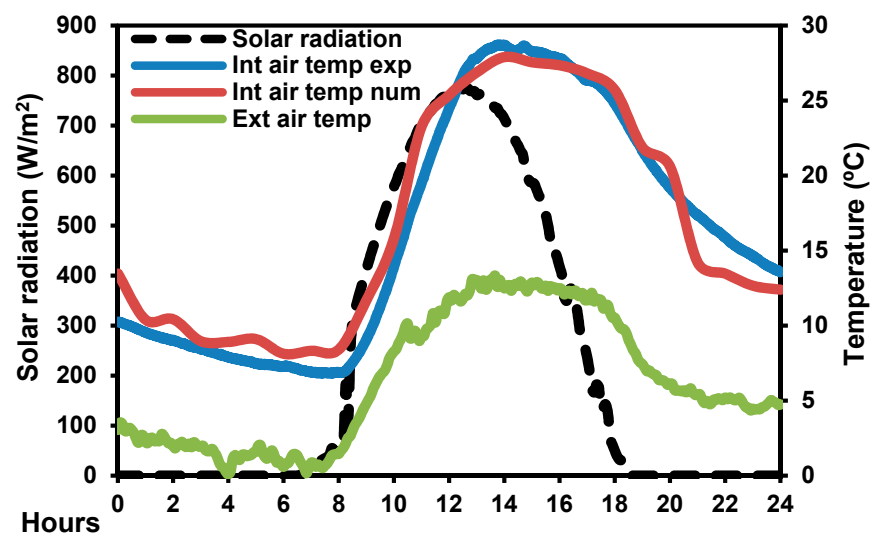

Figure 7. Experimental and numerical simulation data for the 15th of March. Experimental interior air temperature (together with exterior air temperature and solar radiation) and numerical interior air temperature.

Figure 8 presents the thermographs of two interior zones in the sunspace: the sand surface about the middle of the sunspace near the window (top left image) and a view of the interior separation close to the ceiling (bottom left image), including part of the glazing partition at the bottom, the 
opaque wall in the middle and a section of the ceiling at the top. In the same figure, the right images show the temperature contours obtained by numerical simulation. Due to the large differences in the emissivity of the materials, the temperature values cannot be directly compared, but it can be seen that the numerical model reflects the effects of the solar radiation. The top images (the sand bed) show the differences between the zone with direct solar radiation and the zone (top right corner) in the shade of the photovoltaic panels. In the bottom images the different zones are clearly discerned, although in the thermography the ceiling and the glass appear hotter than they really are due to their higher emissivity.

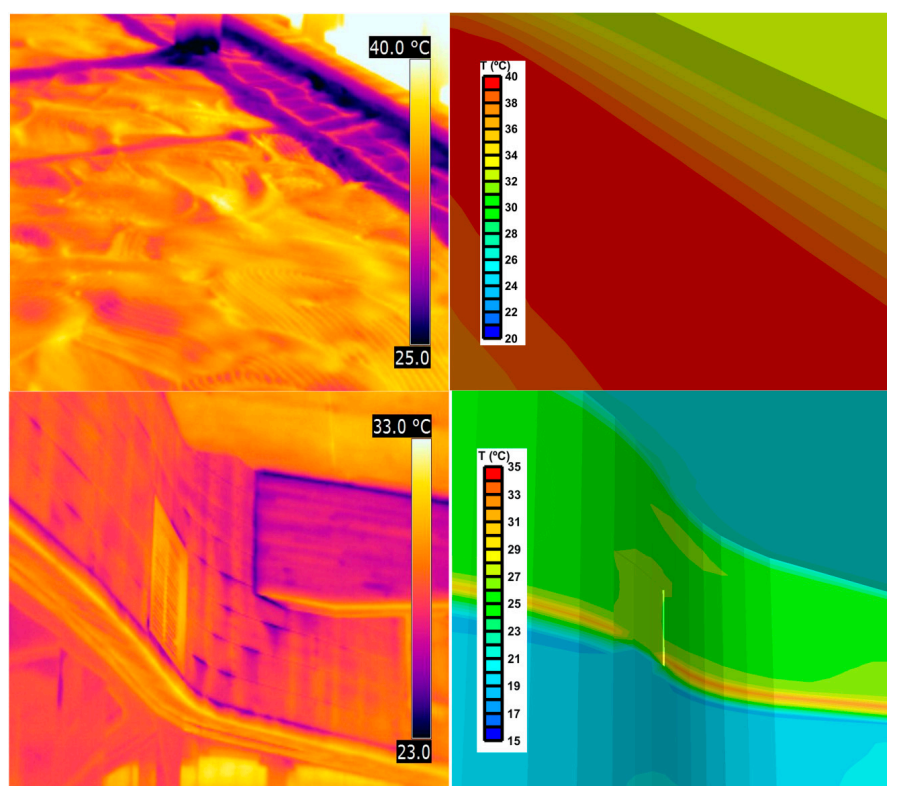

Figure 8. Thermographs of two interior zones in the sunspace: the sand surface (top left) and a view of the interior separation (bottom left); 23rd of February 2012 at 13:00; solar radiation on horizontal surface $713.42 \mathrm{~W} / \mathrm{m}^{2}$, exterior temperature $16{ }^{\circ} \mathrm{C}$. Temperature contours in the same zones using numerical model (right).

\subsection{Heat Storage Analysis}

The floor of this sunspace has a thick sand bed $(20 \mathrm{~cm})$, which acts as a thermal inertia element. The upper part of the layer of sand is in direct contact with the air in the sunspace, and the lower part with a concrete slab with supporting insulation. The sand is heated by the solar radiation in its surface. This thermal energy is transferred to the rest of the sand by conduction and to the air by convection.

Figure 9 shows the variation of the superficial and mean sand temperature throughout the day for the 15th of December. As can be seen, the mean temperature is more uniform throughout the day than the superficial temperature. Both of them overlap basically during the night, without solar radiation, but the superficial temperature becomes up to $4{ }^{\circ} \mathrm{C}$ warmer with solar radiation. Figure 9 also represents the temperature of the exterior and interior air. The surface of the sand and the interior air are about $6{ }^{\circ} \mathrm{C}$ warmer than the exterior air. Besides, during the day the air temperature is slightly higher, while the sand surface is warmer than the air at night. This is because the air not only is warmed up by the sand, but also by the solar energy absorbed by the opaque walls and glazing. Also, the interior air temperature shown is a mean value; the actual temperature of the bottom layer-in contact with the sand-is lower than the sand surface temperature with a net heat transfer to the air.

In Figure 10 the maximum and minimum temperatures of the sand surface are represented throughout the year. In spring and autumn the solar altitude is lower than in summer and thus, the solar radiation enters further in the interior of the sunspace. In winter, with the lowest solar elevation, a considerable quantity of solar energy is transferred too, but not so much because the angle is the 
smallest, and therefore the solar radiation on horizontal surface decreases a lot. Furthermore, the number of sunny days is also lower. The mean temperature of the sand surface increases gradually from winter to autumn. The differences between the maximum and minimum sand surface temperatures are highest in spring and autumn, and lowest in summer, because the temperature is higher at night and the sand cools less.



Figure 9. Superficial and mean temperature of the sand, exterior and interior air temperature for the 15th of December.



Figure 10. Maximum and minimum temperatures of the sand surface for the 15th of March (m), June (j), September (s) and December (d).

Although it is not shown in the figure, the difference between the mean sand temperature and the superficial one-and also the air temperature-is highest in September and March, corresponding to a greater heat transfer.

From the maximum and minimum values of the mean sand temperature it can be calculated that the energy transferred by the sand is about 8.3, 2.8, 7.5 and 5.7 kWh for the 15th of March, June, September and December, respectively.

Figure 11 represents the variation of the temperature inside the sand with the height. The reference position is about a meter away from the exterior glazing surface. The different curves show this inner temperature at several instants along the day (15th March). The sand surface in contact with the slab is considered the zero level, and the sand in contact with the interior air is the $0.20 \mathrm{~m}$ level. The sand surface experiments a high oscillation of the temperature (see also Figure 9). This oscillation is transmitted to the bottom with a strong damping and some delay.

Following its behaviour throughout the day chronologically, it can be seen that from 2:00 a.m. to 6:00 a.m. the sand cools fairly evenly. At 10:00 a.m. it has already started to heat at the upper 
part, while at the bottom it remains even colder than before. There is a net flux of energy to the sand, transmitted from the surface to the bottom. At 14:00 the superficial temperature is very high and it is beginning to increase at the bottom. At 18:00 the temperature of the surface has already started to decrease, while the temperature at the bottom has reached its maximum value. The heat flux is then inverted. The energy is transmitted from the sand to the exterior air starting in the upper part of the sand. At 22:00 the surface is colder than the bottom. From 22:00 to 6:00 a.m. the temperature decreases fairly evenly throughout the depth.

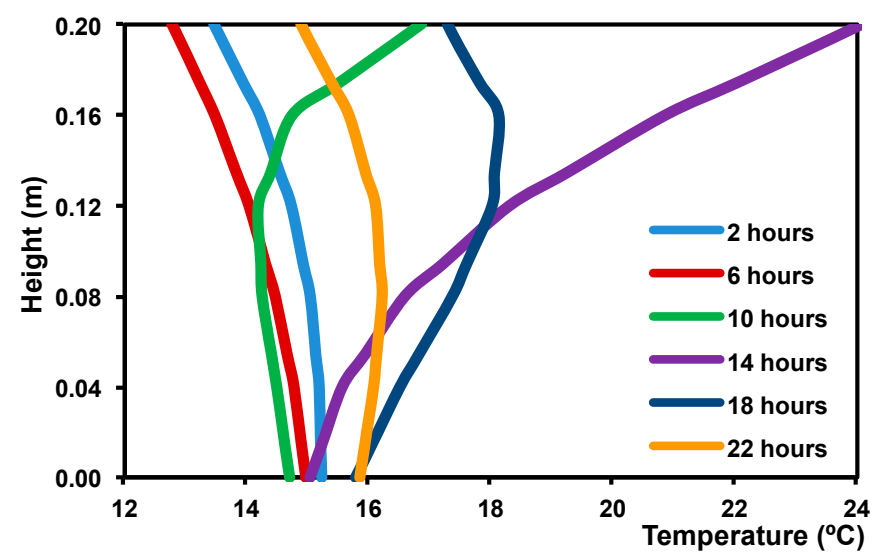

Figure 11. Sand temperature variation with the height for the 15th of March (obtained from CFD simulations).

Looking at the temperature differences at each elevation, it can be said that the upper layer of the sand (from $10 \mathrm{~cm}$ to $20 \mathrm{~cm}$ ) is responsible for about $2 / 3$ of the heat storage and exchange.

\section{Conclusions}

In this paper a thermal analysis of an attached sunspace has been performed. During the ARFRISOL project (Bioclimatic Architecture and Solar Cooling), a demonstrator container was built in northern Spain (Asturias), where this sunspace is located. It is considered a heating passive solar system that enables solar radiation to be collected and accumulated in the floor space. The sunspace consists of a south-facing glazed exterior wall with both clear glass and semi-transparent photovoltaic panels, an intermediate space with a sand floor and a partially glazed interior wall.

An unsteady-state numerical simulation of this attached sunspace has been performed using the CFD code ANSYS. Also, a User-Defined Function (UDF) has been developed in order to set the air temperature, the sun position and solar radiation in function of time. The solar radiation data used in the simulations have been calculated following the ASHRAE method adjusted with the data from the Asturias Solar Map developed by the University of Oviedo in the ARFRISOL project.

The numerical model has been validated using experimental data collected in the sunspace. The interior air temperature obtained by the simulations fits quite well the experimental temperature variations throughout the day. Also, the solar radiation effects on the surfaces can be appreciated, specifically the differences between the sunny and shaded areas.

The sand behaviour has been studied as an inertia element. The sand floor collects and accumulates the solar radiation, and is usually warmer than the interior air. The analysis of the sand and air temperature shows a high heat transfer in spring and autumn, even greater than in winter, but it is damped in summer. The study of the temperature variation inside the sand indicates that most of the heat storage and exchange is in the upper $10 \mathrm{~cm}$ of the sand bed.

Author Contributions: M.J.S.L. and E.B.M. performed the numerical model and the simulations. A.J.G.T. and J.L.P.G. designed and performed the experiments. M.J.S.L. and A.J.G.T. analysed the data (both experimental 
and numerical). E.B.M. and J.L.P.G. compared both experimental and numerical data. M.J.S.L. and E.B.M. wrote the paper.

Acknowledgments: This work was carried out in the framework of the Singular Strategic Project ARFRISOL, on bioclimatic architecture and solar cooling (Reference: PS-120000-2005-1), funded by the Spanish Ministry of Education and Science (MEC) and co-funded by ERDF.

Conflicts of Interest: The authors declare no conflict of interest.

\section{References}

1. International Energy Agency (IEA). Worldwide trends in energy use and efficiency. In Key insights form IEA Indicator Analysis; Head of Communication and Information Office: Paris, France, 2008; Available online: https:/ / www.iea.org/publications / freepublications/publication/Indicators_2008.pdf (accessed on 26 April 2018).

2. Bosqued, A.; Palero, S.; Sanjuan, C.; Soutullo, S.; Enríquez, R.; Ferrer, J.A.; Martí, J.; Heras, J.; Guzmán, J.D.; Jiménez, M.J.; et al. Arfrisol, bioclimatic architecture and solar cooling project. In Proceedings of the PLEA2006 Passive and Low Energy Architecture, Geneva, Switzerland, 6-8 September 2006.

3. Butti, K.; Perlin, J. A Golden Thread: 2500 Years of Solar Architecture and Technology; Van Nostrand Reinhold Co.: New York, NY, USA, 1 April 1980.

4. Fuchs, R.; McClelland, J.F. Passive solar heating of buildings using a transwall structure. Sol. Energy 1979, 23, 123-128. [CrossRef]

5. Jones, R.W. DOE passive and hybrid solar energy program update conference. In Passive Solar Design Handbook; Total Environmental Action, Inc.: Washington, DC, USA, 1981.

6. Jones, R.W.; McFarland, R.D. Attached sunspace heating performance estimates. In Proceedings of the 5th National Passive Solar Conference, Amherst, MA, USA, 19-26 October 1980.

7. Shoda, M.S.; Nayak, J.K.; Bansal, N.K.; Goyal, I.C. Thermal performance of a solarium with renovable insulation. Build. Environ. 1982, 17, 23-32.

8. McFarland, R. Performance Estimates for Attached Sunspace Passive Solar Heated Buildings; Annual Meeting of American Section of the International Solar Energy Society: Phoenix, AZ, USA, 1980.

9. Shaviv, E. The performance of a passive solar house with window sunspace systems. Energy Build. 1984, 7, 315-334. [CrossRef]

10. Bakos, G.C. Energy management method for auxiliary energy saving in a passive-solar-heated residence using low-cost off-peak electricity. Energy Build. 2000, 27, 237-241. [CrossRef]

11. Bakos, G.C. Improved energy management method for auxiliary electrical energy saving in a passive-solar-heated residence. Energy Build. 2002, 34, 699-703. [CrossRef]

12. Nayak, J.K. Transwall versus Trombe wall: Relative performance studies. Energy Convers. Manag. 1987, 27, 389-393. [CrossRef]

13. Fernández-González, A. Analysis of the thermal performance and comfort conditions produced by five different passive solar heating strategies in the United States Midwest. Sol. Energy 2007, 81, 581-593. [CrossRef]

14. Schoenau, G.J.; Lumbis, A.J.; Besant, R.W. Development and verification of a simulation model for predicting the thermal behaviour of attached sunspaces. Energy Convers. Manag. 1991, 32, 319-331. [CrossRef]

15. Bakos, G.C.; Tsagas, N.F. Technology, thermal analysis and economic evaluation of a sunspace located in northern Greece. Energy Build. 2000, 31, 261-266. [CrossRef]

16. Mihalakakou, G. On the use of sunspace for space heating/cooling in Europe. Renew. Energy 2002, 26, 415-429. [CrossRef]

17. Utzinger, D.M.; Klein, S.A.; Mitchell, J.W. The effect of air flow rate in collector-storage walls. Sol. Energy 1980, 25, 511-519. [CrossRef]

18. Roux, J.J.; Teodosiu, C.; Covalet, D.; Chareille, R. Validation of a glazed space simulation model using full-scale experimental data. Energy Build. 2004, 36, 557-565. [CrossRef]

19. Mottard, J.M.; Fissore, A. Thermal insulation of an attached sunspace and its experimental validation. Sol. Energy 2007, 81, 305-315. [CrossRef]

20. Wall, M. Distribution of solar radiation in glazed spaces and adjacent buildings. A comparison of simulation programs. Energy Build. 1997, 26, 129-135. [CrossRef] 
21. Mihalakakou, G.; Ferrante, A. Energy conservation and potential of a sunspace: Sensitivity analysis. Energy Convers. Manag. 2000, 41, 1247-1264. [CrossRef]

22. Bataineh, K.M.; Fayez, N. Analysis of thermal performance of building attached sunspace. Energy Build. 2011, 43, 1863-1868. [CrossRef]

23. Oliveti, G.; Arcuri, N.; Simone, M.D.; Bruno, R. Solar heat gains and operative temperature in attached sunspaces. Renew. Energy 2012, 39, 241-249. [CrossRef]

24. Owrak, M.; Aminy, M.; Jamad-Abad, M.T.; Dehgham, M. Experiments and simulations on the thermal performance of a sunspace attached to a room including heat-storing porous bed and water tanks. Build. Environ. 2015, 92, 142-151. [CrossRef]

25. Monge-Barrio, A.; Sánchez-Ostiz, A. Energy efficiency and thermal behaviour of attached sunspaces, in the residential architecture in Spain. Summer conditions. Energy Build. 2015, 108, 244-256. [CrossRef]

26. Hilliaho, K.; Lahdensivu, J.; Vinha, J. Glazed space thermal simulation with IDA-ICE 4.61 softwareSuitability analysis with case study. Energy Build. 2015, 89, 132-141. [CrossRef]

27. Hilliaho, K.; Mäkitalo, E.; Lahdensivu, J. Energy saving potential of glazed space: Sensitivity analysis. Energy Build. 2015, 99, 87-97. [CrossRef]

28. Guohui, B. A parametric study of Trombe walls for passive cooling of buildings. Energy Build. 1998, 27, $37-43$.

29. Xiande, F.; Yuanzhe, L. Numerical simulation and sensitivity analysis of lattice passive solar heating walls. Sol. Energy 1999, 69, 55-66.

30. Chen, W.; Liu, W. Numerical analysis of heat transfer in a composite wall solar-collector system with a porous absorber. Appl. Energy 2004, 78, 137-149. [CrossRef]

31. Suárez, M.J.; Sarries, I.; Pistono, J. Numerical analysis of the preheating performance of a glazed corridor in an office building. In Proceedings of the WREC08, World Renewable Energy Congress X and Exhibition, Glasgow, Scotland, UK, 19-25 July 2008.

32. Suárez, M.J.; Gutiérrez, A.J.; Pistono, J.; Blanco, E. CFD analysis of heat collection in a glazed gallery. Energy Build. 2011, 43, 108-116. [CrossRef]

33. ASHRAE. Handbook Fundamentals; ASHRAE: Atlanta, GA, USA, 2009.

34. Prieto, J.I.; Martínez-García, J.C.; García, D.; Santoro, R.; Rodríguez, A. Mapa Solar de Asturias; PSE-ARFRISOL: Asturias, España, 2009.

35. Iqbal, M. An Introduction to Solar Radiation; Academic Press: Toronto, ON, Canada, 1983.

36. Freitas, C.J. The issue of numerical uncertainty. Appl. Math. Model. 2002, 26, 237-248. [CrossRef]

37. Modest, M.F. Radiative Heat Transfer, 2nd ed.; Academic Press: Cambridge, MA, USA, 2003.

38. Launder, B.E.; Spalding, D.B. The numerical computation of turbulent flows. Comput. Methods Appl. Mech. Eng. 1974, 3, 269-289. [CrossRef]

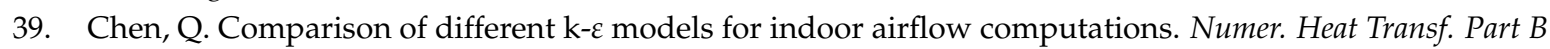
1995, 28, 353-369. [CrossRef]

40. Nicolau, V.P.; Maluf, F.P. Determination of radiative properties of commercial glass. In Proceedings of the PLEA2001 Conference on Passive and Low Energy Architecture, Florinápolis, Brazil, 7-9 November 2001.

41. Government of Spain, Ministry of Public Works. Spanish Technical Building Code (CTE-DB-HE), Official Bullet of the State 74 (Sec.1) (2006). Available online: https://www.codigotecnico.org (accessed on 2 May 2018).

(C) 2018 by the authors. Licensee MDPI, Basel, Switzerland. This article is an open access article distributed under the terms and conditions of the Creative Commons Attribution (CC BY) license (http://creativecommons.org/licenses/by/4.0/). 